\title{
THREAT LIFE CYCLE AND ITS DYNAMICS
}

\author{
Rudolf URBAN ${ }^{\mathrm{a}}$, ̌̌́rka HOŠKOVÁ-MAYEROVÁ \\ ${ }^{a}$ University of Defence, Faculty of Military Leadership, Department of Emergency, Kounicova 65, 662 \\ 10 Brno, Czech Republic; email:rudolf.urban@unob.cz \\ ${ }^{\mathrm{b}}$ University of Defence, Faculty of Military Technology, Department of Mathematics and Physics, \\ Kounicova 65, 66210 Brno, Czech Republic; email:sarka.mayerova@unob.cz,
}

Cite this article: Urban, R., Hošková-Mayerová, Š. (2017). Threat Life Cycle and Its Dynamics. Deturope, 9, 2: 93-109

\begin{abstract}
This article presents a discussion and reflection on the concept of monitoring the life cycle of threats. Furthermore, it indicates that due to the changing environmental conditions, for example, there may also be changes in the evaluation of not only the threat dynamics as a whole, but also of its various phases. This approach, with an emphasis on exploring the dynamics of each phase, is first tested on a hypothetical example. Subsequently, a verification of these considerations is conducted on the example of the development of specific threats - floods on two rivers.
\end{abstract}

Keywords: risk and uncertainty, risk management, crisis management, security, life cycle model, dynamic treatment model

\section{INTRODUCTION}

In the current terminology, the development of threats and risks is described and defined in various specified stages, which in terms of crisis management include the amount of already standardized activities and procedures (King, 2002).

In terms of effectively coping with a crisis, however, the question remains whether existing approaches, which describe the threat development, can truly capture its dynamics over time. This knowledge is liable to affect not only the managerial practices of crisis management, but also in particular the real need of the source of security crisis management in response to the dynamics of its development (the change in risk value) (Silva, \& Klutle, 2016).

The notion of life cycle assessment is, besides the economic environment relating to the development of products (Hendrickson, \& Horvath 1998), most frequently used in connection with the effects of the product on the environment (Jolliet et al., 2003). At present, it is often used in other scientific disciplines testing various hypotheses, e.g. biology (Erikson, 1980), psychology (Katz, \& Kahn, 1978) developmental anthropology, and also in the area of security and terrorism. (Sedlačík, Odehnal, \& Foltyn, 2015). This approach was the initial inspiration for particular reflection on the possible perception of natural hazards in terms of 
their life cycle in a crisis management system and their subsequent monitoring as a complex process. A life cycle in its universality is a system of developmental stages or elementary stages, defined as the phase of growth, maturity and inhibition of tangible or intangible activities, i. e. the process starting with their creation and ending with their cessation. As the economic and production environment of companies and living organisms evolves, environmental changes to global or local environments occur. These changes may generate symmetric or asymmetric threats, the evolution of which may influence the entire life cycles. (Levitt, 1965).

Threat life cycle can be broadly defined in five phases - prenatal phase, phase of formation, incidence phase, phase of secondary effects, and phase of cessation. The cycle defined in this way allows the expression of certain assumptions on possible ways of threat adaptation to changing environmental conditions, representing a potential source for external and internal developmental variability of a threat. Environmental changes may significantly affect the overall progress of the threat life cycle, particularly of a natural character. The decisive evolutionary parameters influencing both internal and external threat dynamics include the criterion of "time".

Based on the life history of past threats it can be stated that the progress, and especially dynamics, of current threats have changed substantially. Today, crisis managers consider new concepts in their predictions, for example in the case of floods; they use the term "100-year or 1,000-year flood." In terms of threat development, which compared to the past means a completely different dimension of understanding of its course, the ensuing needs and their solutions. The above mentioned fact indicates not only that the life cycle changes as a whole, but also that progress and dynamism change within individual threat life cycle stages. For future crisis management it is important to see changes among the different stages of development, particularly in terms of the dynamics of their progress. Each threat's development phase may show a typical pattern of developmental changes. Individual phases may vary in the extent, rate, and nature of such changes. Transition, especially between stages of natural threats, may be affected, for example, by the extent of urbanization or other artificial human interventions in nature. Changes in the development of population lifestyle, disturbance in the balance of nature, etc., may have their impacts (Bumbová, Božek, \& Čáslavský, 2012) also on the asymmetric life cycle development in the category of natural threats. Each type of threat may have a sequence of development, duration and dynamics of its stages different. 
It is particularly significant for such an approach, being discussed in terms of the theory of crisis management, that it allows potential crisis situations to be inspected not only comprehensively, but also individually through different phases over time. This analyticsynthetic approach could allow a more efficient process of contingency planning, as well as the actual deployment of human, financial and material resources (Urban, 2014).

The following figure (Fig. 1) shows the threat's life cycle phases in connection with the phases of crisis management commonly defined in current literature.

Figure 1 Life-cycle phase

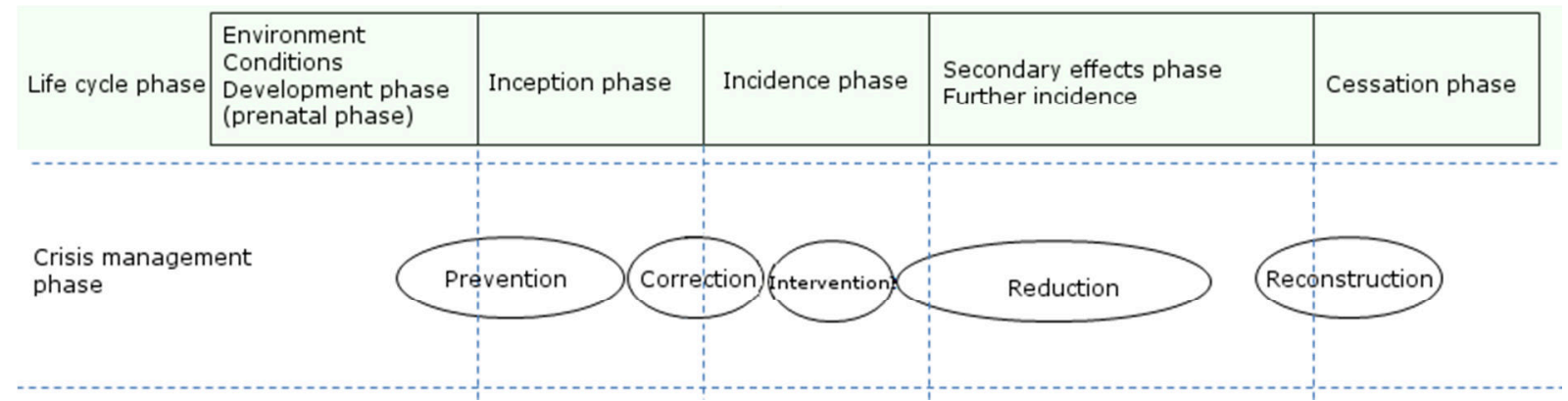

Source: Antušák \& Kopecký (2003) and Hendrych (2008).

First, the so-called prenatal phase is a stage characterized by the development of conditions that pave the way of the emergence of new threats that are able to exert themselves and to have a negative effect on health, property, and the human environment. Preventive action is currently typical for crisis management, see picture above.

At the moment of imminent danger we talk, in terms of life cycle, about the stage of risk growth. For this phase the beginning of the growth of risk is typical, i.e. the likelihood that a threat with increasing time will have a negative impact on its surroundings. From the perspective of the crisis the elevation phase begins. For crisis management it means to launch first correction processes.

The next stage of the threat life cycle is "incidence". At this moment, hazard (e.g. river) begins to have negative effects on human environment (river begins to rise above its banks $=$ flood threat). Threat goes from elevation to escalation and crisis management tries to intervene through active implementation of measures in order to reduce the risk of escalation and prevent a crisis situation from occurring.

The following phase of the life cycle is the phase of "further incidence and secondary effects" (swollen river remains in its culmination point and besides its own negative impacts it creates conditions for the occurrence of other threats; it has consequent impacts). The critical situation is in the phase of culmination and begins to pass into a state of consolidation. Crisis 
management keeps reduction measures and directs the situation into the phase of restoration measures. Crisis situation ceases.

Cessation is the last stage of the threat life cycle. Due to environmental changes, the threat completely ceases, or is suppressed to a latent state. Under suitable conditions it moves to the phase of formation again.

Threat in the above discussed approach represents a multi-criterial function, the individual criteria of which are time, the probability of occurrence, and impact. Risk at different times and threat's different life cycle stages take different values. The knowledge of threat dynamics is substantial for the process of risk control and management. With a growing risk the requirement to adopt a measure that would move this risk to the area of a tolerable risk increases as well. Such measures (not only in the planning stage - preventive phase) require financial, material, and human resources. Based on the economic recognition that resources are limited, the threat assessment in terms of its life cycle allows focusing on the individual stages of risk so that we have resources allocated on a "just in time" principle, i. e. effectively.

Verification of the above mentioned considerations on threat evolution with particular emphasis on threat dynamics within each stage of its development will be conducted in two phases of testing. The first phase was based on the life-cycle model and the second phase was the data on real crisis situation from the past.

\section{Mathematical modelling of a theoretical design of the threat life cycle function}

Threat life cycle has its phases which have, in terms of time, their own sequence and continuity. The basic attribute that can be observed in these phases with respect to time, is the already mentioned level of risk, whose dynamics is captured graphically through the theoretical model of threat life cycle and its dynamics as shown in Figure 2. The first chapter includes a model which is constructed on the basis of model-set time shift values of threat development in its various phases. Thus the model allows pretesting of the expected dynamic shifts in the threat life cycle. 
Figure 2 Threat Life Cycle Dynamics

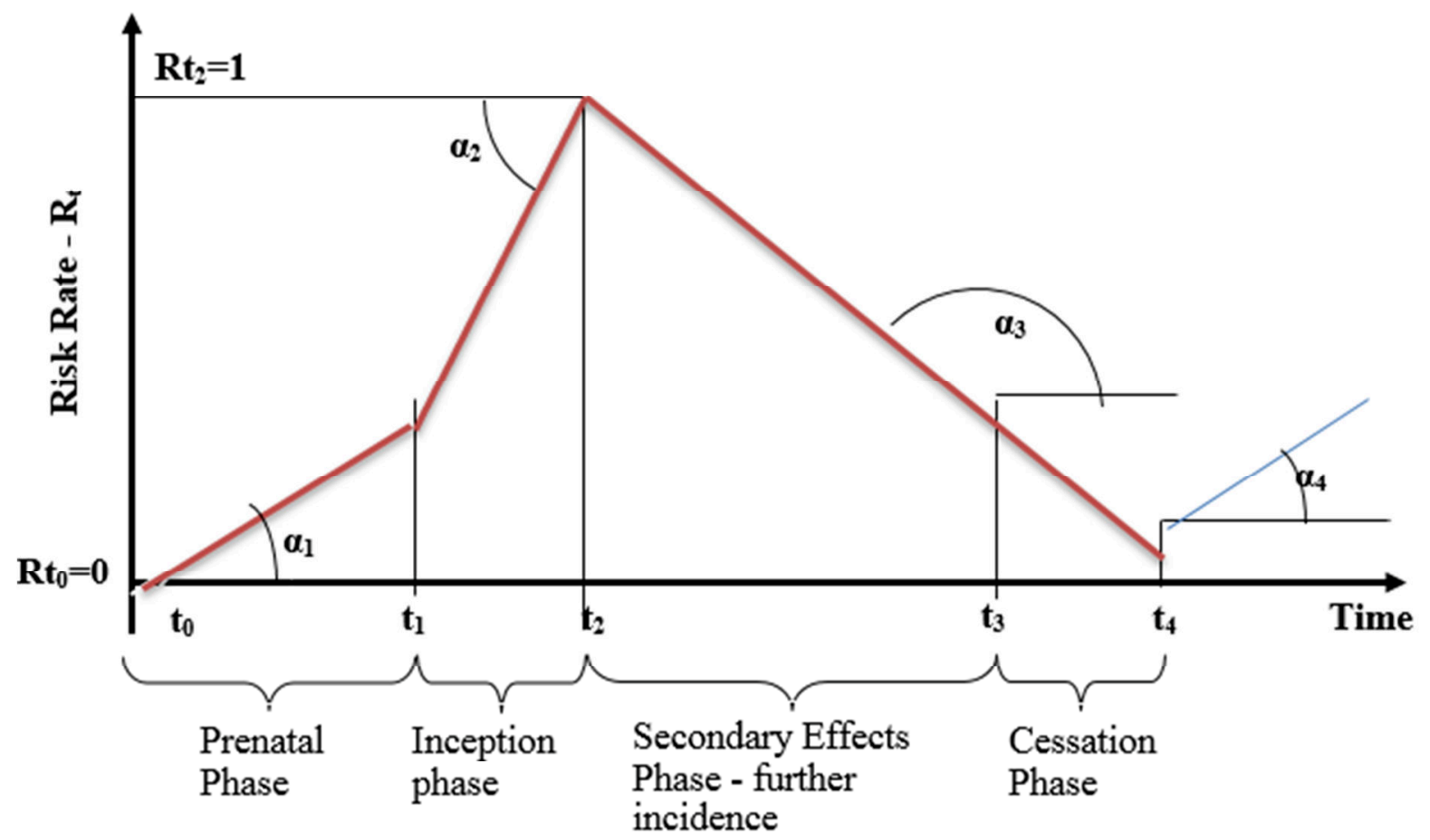

Source: Urban (2013), ti ...time; Rt ...risk rate at time t

Function introduced in the model defines the level of risk within each phase. When looking at the threat as a system variable in time, we get the typical curve of the course of threat risk within the entire life cycle. The function progress validity will be verified on the basis of two independent observations (real floods) in such a theoretically proposed model. The validity verification will either confirm or contradict the characteristic shape of threat life cycle function generally applicable also to other natural threats.

To verify the relationships above, a hypothetical model example with the following input values is considered. The initial time $t_{0}=0$ (the beginning of formation phase), with breakpoints at the times $t_{1}=0.5, t_{2}=0.8$ (the beginnings of other phases), with the transition time $t_{3}=1.6$ and the end time (threat cessation) $t_{4}=2$. Let us considered ten nonequidistant ordered pairs of values of time and degree of risk, which express the dynamic progress of threat in various stages of the life cycle, are considered: $[0,0.1],[0.2,0.2]$, $[0.5,0.3],[0.6,0.6],[0.7,0.9],[0.8,1.0],[1.0,0.8],[1.3,0.6],[1.7,0.3],[2.0,0.1]$.

\section{METHODOLOGY - PIECEWISE-LINEAR APPROXIMATION FUNCTION}

The above breakpoints $[0.5,0.3]$ and $[0.8,1.0]$ are included in the calculation always into both neighbouring approximation lines.

The first line $y=a x+b$ starting from the point $[0,0.1]$ with the direction $a=\operatorname{arctg} \alpha_{1}>$ 0 determined by the method of the smallest squares best conducted in the vicinity of the two 
other points $[0.2,0.2],[0.5,0.3]$. The second approximation line $y=c x+d$, where $c=$ $\operatorname{arctg} \alpha_{2}>0$, will be determined by four points [0.5,0.3], [0.6,0.6], [0.7,0.9], [0.8,1.0]. Third approximation line $y=e x+l$ with a negative slope $e=\operatorname{arctg} \alpha_{3}<0$ will lead near the five points $[0.8,1.0],[1.0,0.8],[1.3,0.6],[1.7,0.3],[2.0,0.1]$.

Recall, that during a linear regression, i. e. during the approximation of given $n$ points $\left[x_{i}, y_{i}\right], i=1,2, \ldots, n$, in the plane by a line of equation of the direction form $y=k x+q$, a respective linear system of two equations by two unknown parameters $\mathrm{k}$ and $\mathrm{q}$ (i. e. normal system (1)) has the form as follows

$$
\begin{gathered}
k \sum_{i=1}^{n} x_{i}+q n=\sum_{i=1}^{n} y_{i}, \\
k \sum_{i=1}^{n} x_{i}^{2}+q \sum_{i=1}^{n} x_{i}=\sum_{i=1}^{n} x_{i} y_{i} .
\end{gathered}
$$

a) In case of the first approximation straight line, more specifically half line, $y=a x+b$, where $\mathrm{k}=\mathrm{a}$ and $\mathrm{q}=\mathrm{b}$, the system of normal equations is obtained:

$$
a \sum_{i=1}^{3} x_{i}+3 b=\sum_{i=1}^{3} y_{i}, \quad a \sum_{i=1}^{3} x_{i}^{2}+b \sum_{i=1}^{3} x_{i}=\sum_{i=1}^{3} x_{i} y_{i}
$$

Because $\sum_{i=1}^{3} x_{i}=0.7, \quad \sum_{i=1}^{3} y_{i}=0.6, \quad \sum_{i=1}^{3} x_{i}^{2}=0.29, \quad \sum_{i=1}^{3} x_{i} y_{i}=0.19$, a set of equations is received in the form $0.7 a+3 b=0.6,0.29 a+0.7 b=0.19$

Solution of the system is $a=0.3947, b=0.1079$, the first approximate line (half line) thus has the equation $\mathrm{fl}: \mathrm{y}=0.3947 \mathrm{x}+0.1079$, so starting from the point $[0,0.1079]$ and intersecting for example the point [0.5,0.3276].

b) Normal system (1) for the second approximation line $y=c x+d$, which is determined by four points $[0.5,0.3],[0.6,0.6],[0.7,0.9],[0.8,1.0]$, has the form as follows

$$
c \sum_{i=1}^{4} x_{i}+4 d=\sum_{i=1}^{4} y_{i}, \quad c \sum_{i=1}^{4} x_{i}^{2}+d \sum_{i=1}^{4} x_{i}=\sum_{i=1}^{4} x_{i} y_{i} .
$$

Because $\sum_{i=1}^{4} x_{i}=2.6, \quad \sum_{i=1}^{4} y_{i}=2.8, \quad \sum_{i=1}^{4} x_{i}^{2}=1.74, \quad \sum_{i=1}^{4} x_{i} y_{i}=1.94$, a set of equations is received in the form

$$
2.6 c+4 d=2.8,1.74 c+2.6 d=1.94 .
$$

Solution of the system is $c=2.4$ a $d=-0.86$, so the second approximation line thus has the equation $\boldsymbol{f}_{2}: \boldsymbol{y}=\mathbf{2 . 4} \boldsymbol{x} \mathbf{- 0 . 8 6}$. It intersects for example points $[0.5,0.34]$ and $[0.8,1.06]$.

c) Normal system for the third approximation line $y=e x+l$, which is determined by five points $[0.8,1.0],[1.0,0.8],[1.3,0.6],[1.7,0.3],[2.0,0.1]$, has the form as follows 


$$
e \sum_{i=1}^{5} x_{i}+5 l=\sum_{i=1}^{5} y_{i}, e \sum_{i=1}^{5} x_{i}^{2}+l \sum_{i=1}^{5} x_{i}=\sum_{i=1}^{5} x_{i} y_{i}
$$

Because $\sum_{i=1}^{5} x_{i}=6.8, \quad \sum_{i=1}^{5} y_{i}=2.8, \quad \sum_{i=1}^{5} x_{i}^{2}=10.22, \quad \sum_{i=1}^{5} x_{i} y_{i}=3.09$, a set of equations is received in the form

$$
6.8 e+5 l=2.8, \quad 10.22 e+6.8 l=3.09 .
$$

Solution of the system is $e=-359 / 486 \doteq-0.7387$ and $l=\frac{1901}{1215} \doteq 1.5646$, so the third approximation line thus has the equation $\boldsymbol{f}_{3}: \boldsymbol{y}=\mathbf{- 0 . 7 3 8 7 x}+\mathbf{1 . 5 6 4 6}$, so it intersects e.g. points $[0.8,0.9736]$ and $[2.0,0.0872]$. Then we find the intersection of the graphs of the first two approximation lines $y=0.5862 x$ and $y=2.4 x-0.86$, which is the point A with the coordinates approximately $[0.47,0.28]$, and also the intersection of the graphs of the other two approximation lines $y=2.4 x-0.86$ a $y=-0.7387 x+1.5646$ which is the point $\mathrm{B}$ of coordinates approximately $[0.77,0.99]$. Standard error of approximation of chosen 10 points using the piecewise linear function is

$$
S_{f}=\sqrt{\sum_{i=1}^{10}\left|f\left(x_{i}\right)-y_{i}\right|^{2}} \doteq \sqrt{0.0779} \doteq 0.279 \text {. }
$$

Figure 3 below shows the ten points in a plane considered at the beginning and the piecewise-linear approximation function.

Figure 3 Model Example - Threat Life Cycle Dynamics

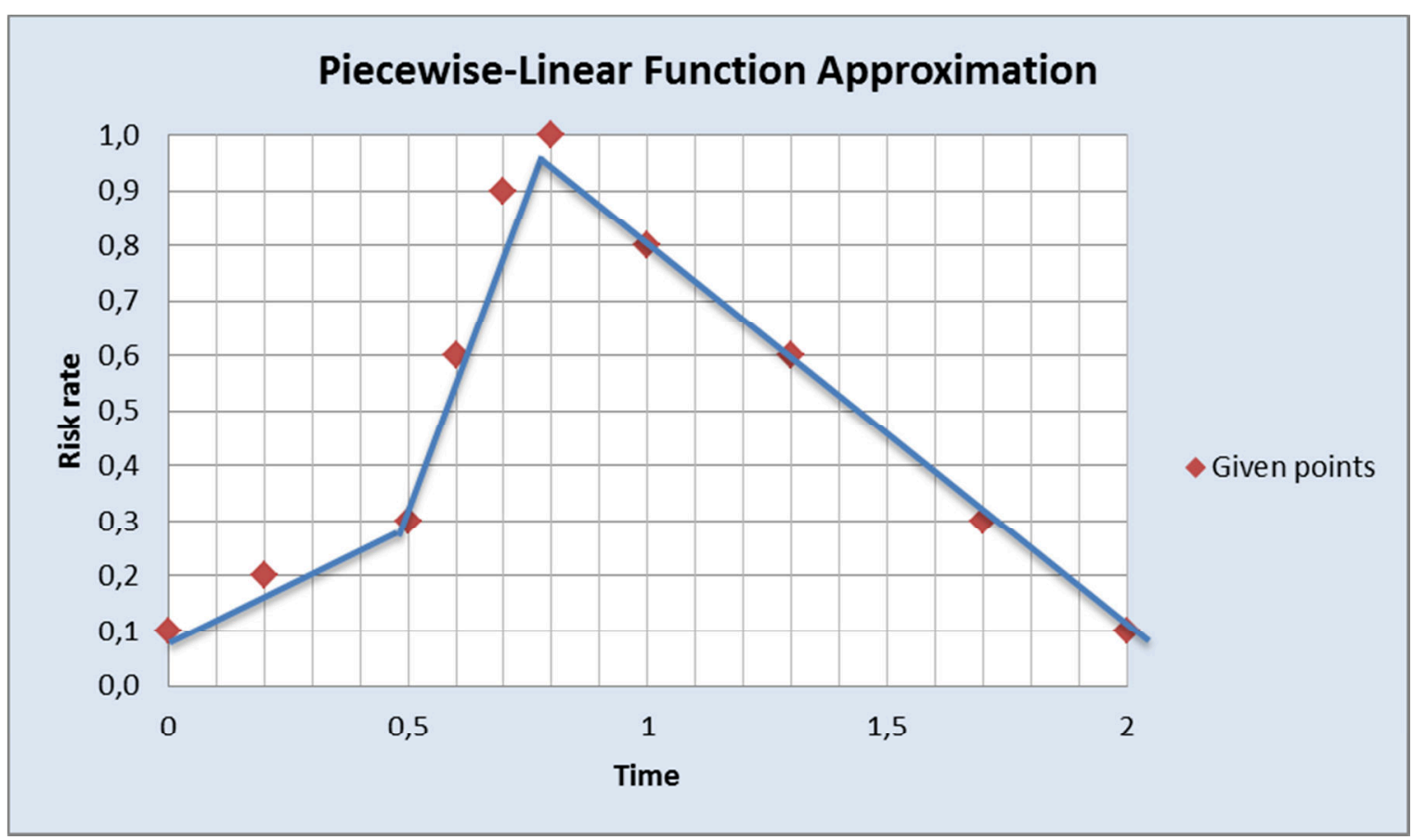

Source: own modelling 
Piecewise-linear approximation function in the event of a model example demonstrates the expected risk development dynamics in threat lifecycle phases.

\section{RESULTS - REAL EXAMPLES}

The above-defined threat lifecycle model will be verified in the second stage of testing the risk dynamics development. The verification will be conducted in different phases on the data sets collected during the floods in the Czech Republic in 2013 - namely on two data sets concerning water levels of the Otava River in the town of Pisek and the Blanice River in Heřmaň settlement. The method of approximation was used for the testing while applying eight types of different functions (quadratic, cubic, etc.) - using the method of the least squares. A comparison of standard errors of these eight types of approximations implies that the significantly smallest approximation error is in case of approximation through linear toggle function, which is thus the most suitable approximation and was therefore used for the final testing. (Hasilová, 2014; Valis, Hasilova, \& Leuchter, 2016).

\section{Case 1 - The Otava River Floods in the Town of Pisek}

Considered are implicit data of the Otava River levels included in the 2013 floods report (Písek Municipal Authority, 2013), (Votýpka, 2014). Data are presented in a diagram covering the time span from 30 May to 7 June 2013. Reading the diagram (Fig. 4) below, 17 data may be identified in the form of ordered pairs, the first element in which is the duration of crisis situation in the halves of day, which means it is equidistant, while the second element represents the water level in metres (rounded to nearest five centimetres): $[0,1.1],[1,1.1]$, $[2,1.15],[3,1.55],[4,1.85],[5,1.8],[6,2.2],[7,3.7],[8,4.5],[9,5.2],[10,4.85],[11,4.3]$, $[12,3.95],[13,3.75],[14,3.45],[15,3.25],[16,3.15]$.

Intersections of partial linear functions - points $[5,1.8]$ and $[9,5.2]$ may be considered the breaking points. Relevance of points, as measured values, to the partial linear functions is determined by a graphical presentation of measured values, and so that the points $[5,1.8]$ and $[9,5.2]$ can be regarded as natural dividing points for each linear function. 
Figure 4 The Otava River Levels in the Town of Pisek

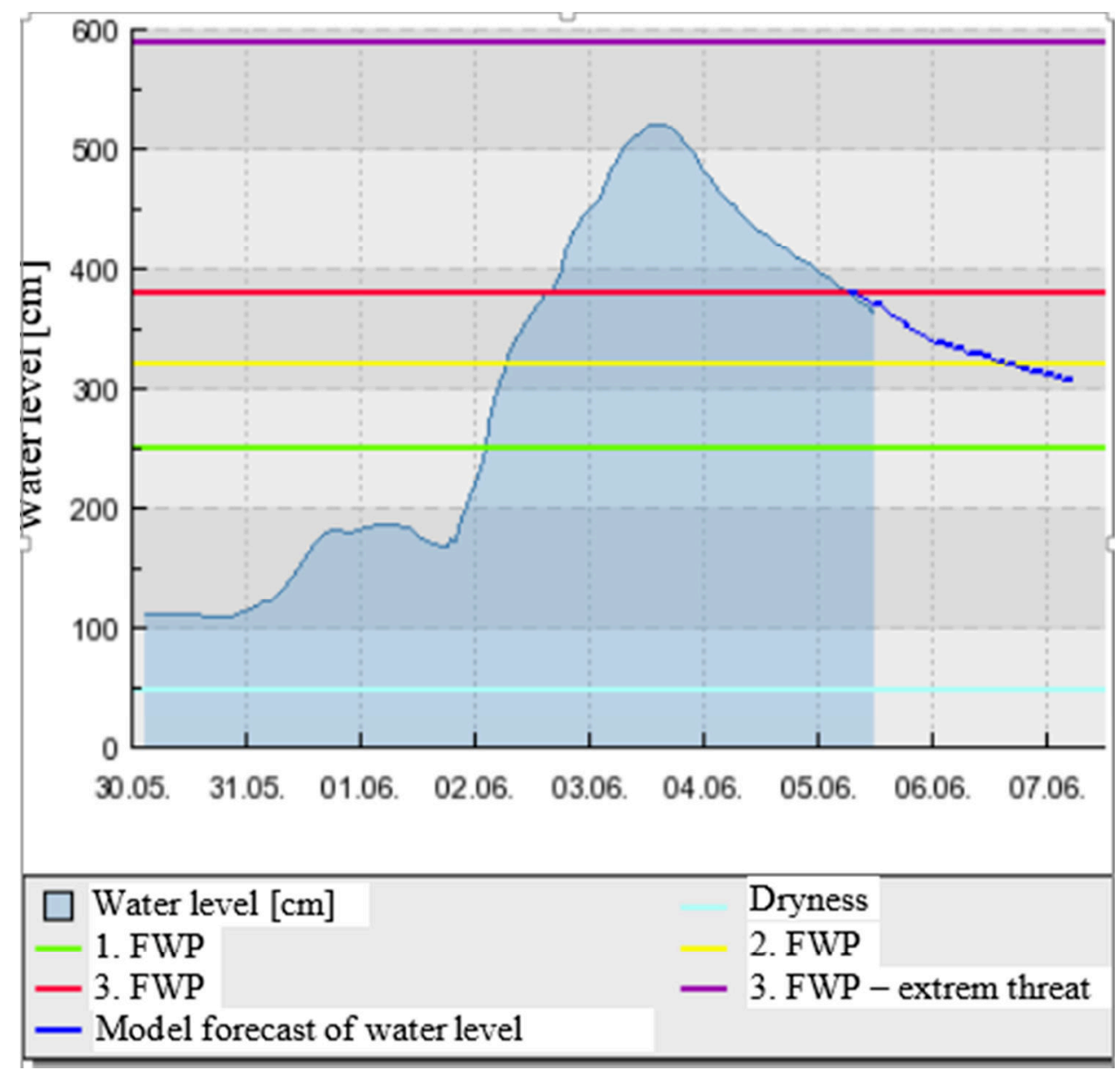

Source: Písek Municipal Authority (2013); FWP - flood warning phase

\section{Piecewise-Linear Function Approximation}

The first approximation straigh line $f_{1}: y=a x+b$ is determined by six points $[0,1.1]$, $[1,1.1],[2,1.15],[3,1.55],[4,1.85],[5,1.8]$, the second approximation straight line $f_{2}: y=$ $c x+d$ is determined by five points [5,1.8], [6,2.2], [7,3.7], [8,4.5], [9,5.2] and the third approximation straight line $f_{3}: y=e x+l$ is determined by eight points [9,5.2], [10,4.85], $[11,4.3],[12,3.95],[13,3.75],[14,3.45],[15,3.25],[16,3.15]$. The related normal systems (1) get the forms as follows:

$$
\begin{gathered}
15 a+6 b=8.55,55 a+15 b=24.45, \\
35 c+5 d=17.4, \quad 255 c+35 d=130.9, \\
100 e+8 l=31.9, \quad 1292 e+100 l=386.2 .
\end{gathered}
$$

$a, c, e$ are real constants representing line directions, $b, d, l$ are real constants representing the point at which the appropriate line crosses the y-axis. The solutions $a=123 / 700, b=$ 
$69 / 70, \quad c=91 / 100, d=-289 / 100, e=-251 / 840, \quad l=6487 / 840$ determine the equations of each of the approximation lines:

$f_{1}: y=0.1757 x+0.9857, f_{2}: y=0.91 x-2.89, f_{3}: y=-0.2988 x+7.7226$.

The coordinates of the cross points of the lines $f_{1}$ and $f_{2}$ and the lines $f_{2}$ and $f_{3}$ are approximately $[5.28,1.91]$ and $[8.78,5.10]$. Standard error Sf of piecewise-linear function approximation is:

$$
S_{f}=\sqrt{\sum_{i=1}^{17}\left|f\left(x_{i}\right)-y_{i}\right|^{2}} \doteq \sqrt{0.4345} \doteq 0.6592 .
$$

The Otava River levels represented by the mentioned seventeen points in a plane and the piecewise-linear function approximation (broken line) are shown in the following diagram:

Figure 5 Threat Life Cycle Dynamics on the Otava River

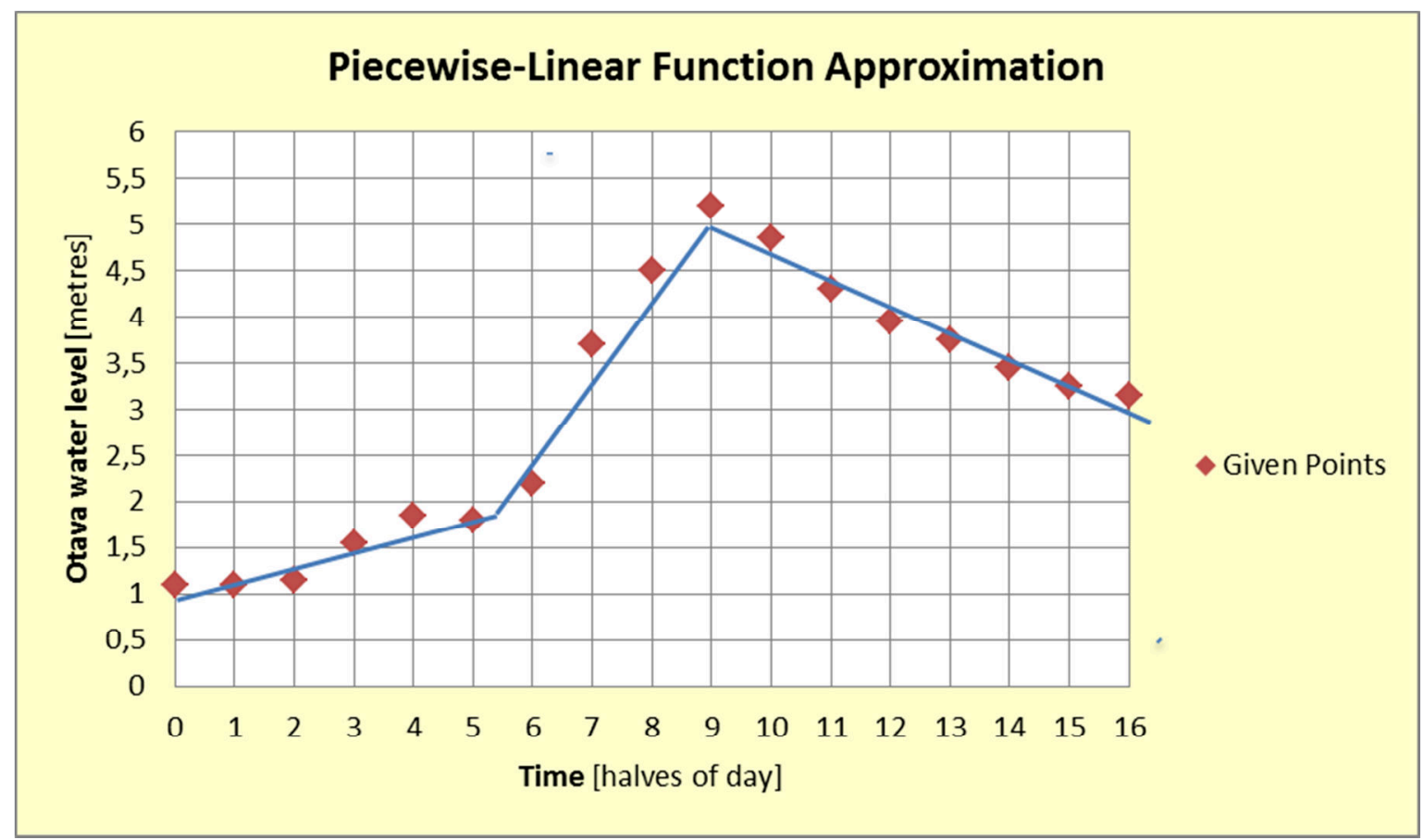

Source: own modelling

\section{Approximation by Other Seven Types of Functions}

The determined data will be approximated by seven types of functions in the following paragraphs:

quadratic function

cubic function

linear-exponential function

linear-logarithmic function

linear-irrational function

$$
\begin{gathered}
y=a x^{2}+b x+c, \\
y=a x^{3}+b x^{2}+c x+d, \\
y=a+b x+c \mathrm{e}^{-x}, \\
y=a+b(x+1)+c \ln (x+1), \\
y=a+b x+c \sqrt{x},
\end{gathered}
$$


linear-goniometric function

$$
\begin{aligned}
& y=a+b x+c \sin x+d \cos x, \\
& y=a+\frac{b}{x+1}+\frac{c}{(x+1)^{2}}
\end{aligned}
$$

The approximation by the least squares method will be done using the special packages of Maple 16 computer algebra system. The formulas for the approximation functions, approximation standard errors and Bayesian information criterion (BIC) together with the piecewise-linear function approximation are given in Table 1 below.

Table 1 The Otava River Water Level Data Approximation by Eight Types of Functions,

\begin{tabular}{|c|c|c|c|}
\hline $\begin{array}{l}\text { Approximation } \\
\text { function }\end{array}$ & $\begin{array}{l}\text { Rough formula of the approximation } \\
\text { function }\end{array}$ & $\begin{array}{l}\text { Standard } \\
\text { error }\end{array}$ & BIC \\
\hline quadratic & $y=-0.0326 x^{2}+0.7144 x+0.1410$ & 2.664 & $-6,345$ \\
\hline cubic & $\begin{array}{c}y=-0.0044 x^{3}+0.0726 x^{2}+0.0615 x \\
+0.8771\end{array}$ & 2.102 & $-11,502$ \\
\hline linear-exponential & $y=1.059+0.2741 x-0.0000003155 \mathrm{e}^{\mathrm{x}}$ & 3.168 & $-0,464$ \\
\hline linear-logarithmic & $y=0.2033-0.03764 x+1.567 \ln (x+1)$ & 3.496 & 2,893 \\
\hline linear-irrational & $y=0.2527-0.07929 x+1.289 \sqrt{x}$ & 3.601 & 3,893 \\
\hline linear-goniometric & $\begin{aligned} y=1.462+0.1909 x \\
-0.08946 \cos x \\
+0.005617 \sin x\end{aligned}$ & 3.904 & 9,480 \\
\hline broken rational & $\begin{array}{r}y=4.8651-14.0515 /(x+1) \\
+10.3747 /(x+1)^{2}\end{array}$ & 3.209 & $-0,0246$ \\
\hline piecewise-linear & $\begin{array}{ll}y=0.1757 x+0.9857, & x \in\langle 0,5.28\rangle \\
y=0.91 x-2.89, & x \in\langle 5.28,8.78\rangle \\
y=-0.2988 x+7.7226, & x \in\langle 8.78,16\rangle\end{array}$ & 0.659 & $-46,044$ \\
\hline
\end{tabular}
Approximation Standard Errors and BIC

Source: own calculation

The comparison of the standard errors of the eight types of approximation imply that the least approximation error is for the piecewise-linear approximation function which makes this approximation most suitable one.

The Bayesian information criterion (BIC) is a criterion for model selection among a finite set of models; the model with the lowest BIC is preferred. In terms of the residual sum of squares (RSS) the BIC is:

$$
B I C=\mathrm{n} \ln \left(\frac{R S S}{n}\right)+\mathrm{k} \ln n,
$$

where $n$ is the number of data points in $x$ is the number of observations, or equivalently, the sample size; $k$ is the number of free parameters to be estimated. If the model under consideration is a linear regression, $k$ is the number of regressors, including the intercept. Piecewise linear function has the smallest value even of this criterion, therefore it is the best approximation. The graphs of all above-mentioned approximation functions are shown in Figure 6. 
Figure 6 The Otava River Water Levels - Diagrams of Data and Approximation Functions

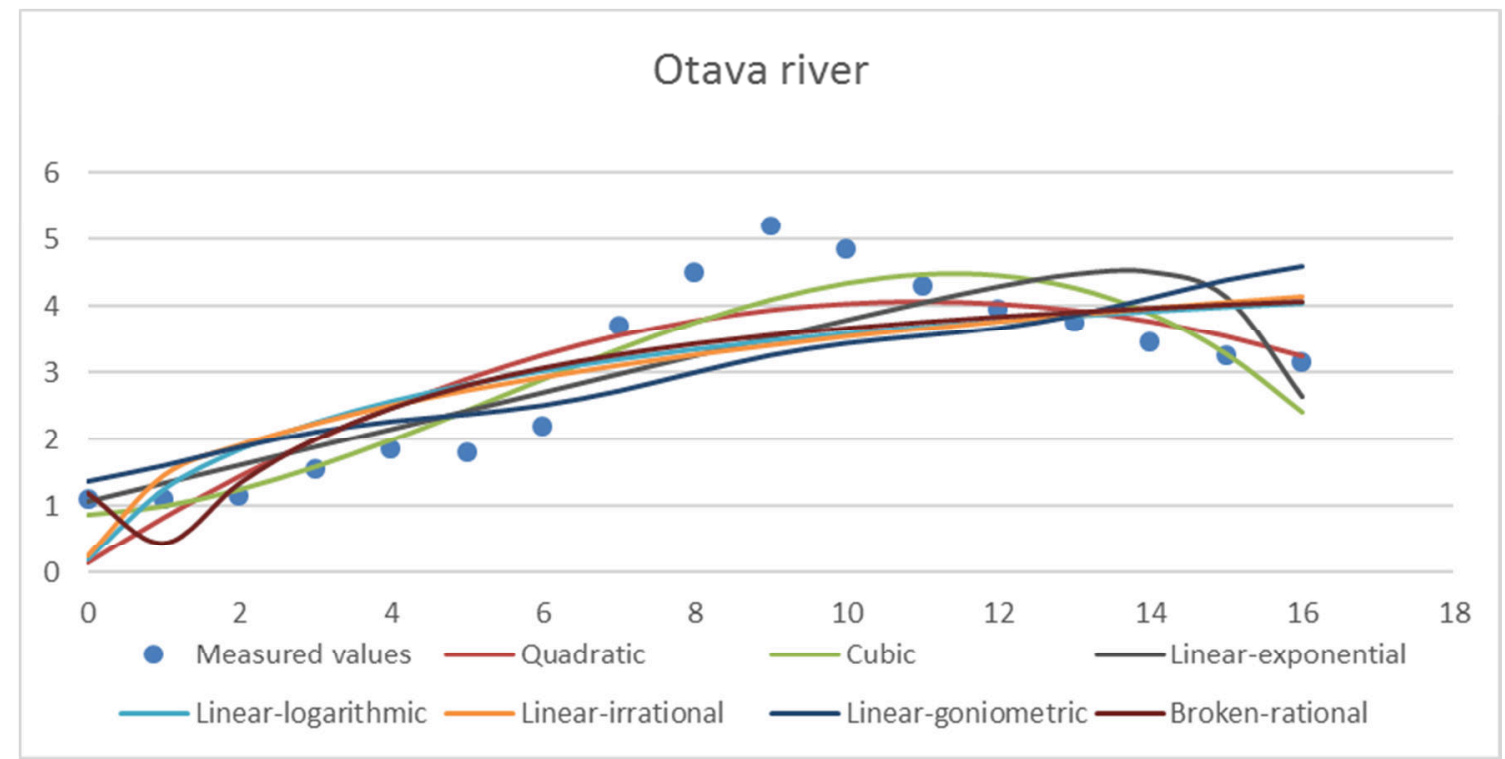

Source: own modelling

\section{Case 2 - The Blanice River Levels in Heřmaň Settlement}

The data on 17 water levels of the Blanice river in Herman settlement can be read from the graph in Figure 7, among other things. The data are in ordered pairs, where the first component is the duration of the crisis in half-days and the second component is the approximate height of the water level in meters (rounded up to five centimetres): $[0,0.5]$, $[1,0.5],[2,0.6],[3,0.75],[4,0.8],[5,0.75],[6,1.15],[7,2.05],[8,2.5],[9,2.75],[10,2.6]$, [11,2.45], [12,2.35], [13,2.3], [14,2.2], [15,2.15], [16,2.1].

The points $[5,0.75]$ and $[9,2.75]$ may be considered the breaking points. The seventeen points will be first approximated by piecewise-linear function $f$ composed of partial straight lines defined by the following equations in direction forms $f_{1}: y=a x+b, f_{2}: y=c x+d$ and $f_{3}: y=e x+l$, while the piecewise-linear function $\mathrm{f}$ will result from the lines linked in their crossing points. Here again, a, b, c, d, e, l represent real constants. The standard error $\mathrm{S}_{\mathrm{f}}$ of this approximation will be compared to the standard errors of other functions. Then again the most suitable type of approximation will be selected. 
Figure 7 The Blanice River Water Level in Heřmaň Settlement
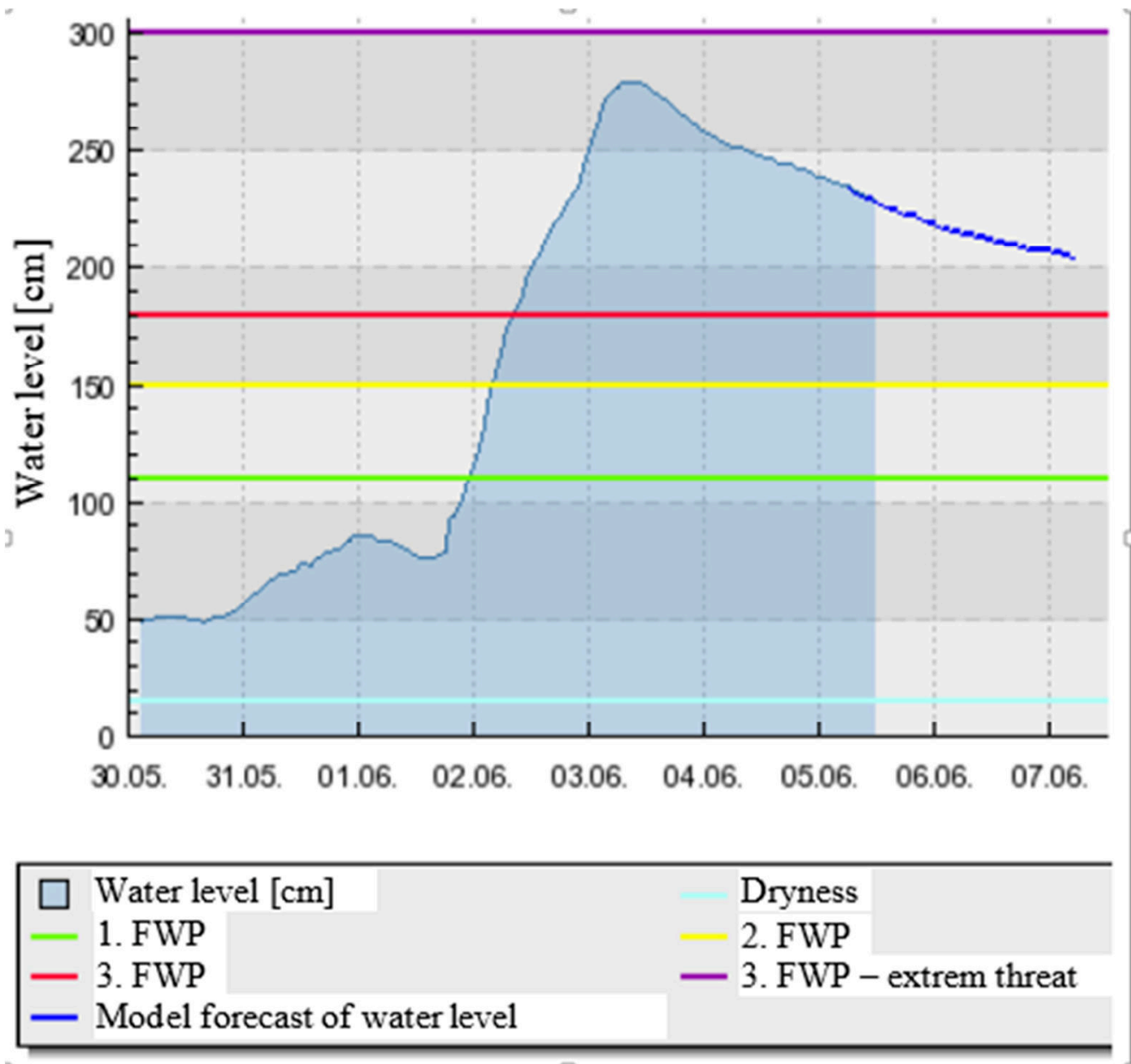

Source: (Písek Municipal Authority, 2013); FWP - flood warning phase

\section{Piecewise-Linear Function Approximation}

The first approximation line $f_{1}: y=a x+b$ is determined by six points $[0,0.5],[1,0.5]$, $[2,0.6],[3,0.75],[4,0.8],[5,0.75]$, the second approximation line $f_{2}: y=c x+d$ is determined by five points $[5,0.75],[6,1.15],[7,2.05],[8,2.5],[9,2.75]$ and the third approximationline $f_{3}: y=e x+l$ is determined by eight points [9,2.75], [10,2.6], [11,2.45], [12,2.35], [13,2.3], $[14,2.2],[15,2.15],[16,2.1]$. The related normal systems (1) get the forms as follows:

$$
\begin{aligned}
& 15 a+6 b=3.9, \quad 35 c+5 d=9.2, \quad 100 e+8 l=18.9, \\
& 55 a+15 b=10.9, \quad 255 c+35 d=69.75, \quad 1292 e+100 l=232.45 .
\end{aligned}
$$

The solutions $a=23 / 350, b=17 / 35, c=535 / 1000, d=-1905 / 1000, \quad e=$ $-19 / 210, l=5869 / 1680$ determine the approximation lines:

$$
f_{1}: y=0.0657 x+0.4857, f_{2}: y=0.535 x-1.905, f_{3}: y=-0.0905 x+3.4935 \text {. }
$$

The coordinates of the cross points of the lines $f_{1}$ and $f_{2}$ and the lines $f_{2}$ and $f_{3}$ are approximately $[5.09,0.82]$ and $[8.63,2.71]$. Standard error of piecewise-linear function 
approximation $S_{f}=\sqrt{\sum_{i=1}^{17}\left|f\left(x_{i}\right)-y_{i}\right|^{2}} \doteq \sqrt{0.1131} \doteq 0.3363$. The seventeen points in a plane and the approximations are shown in the Figure 8.

Figure 8 Threat Life Cycle Dynamics on the Blanice River

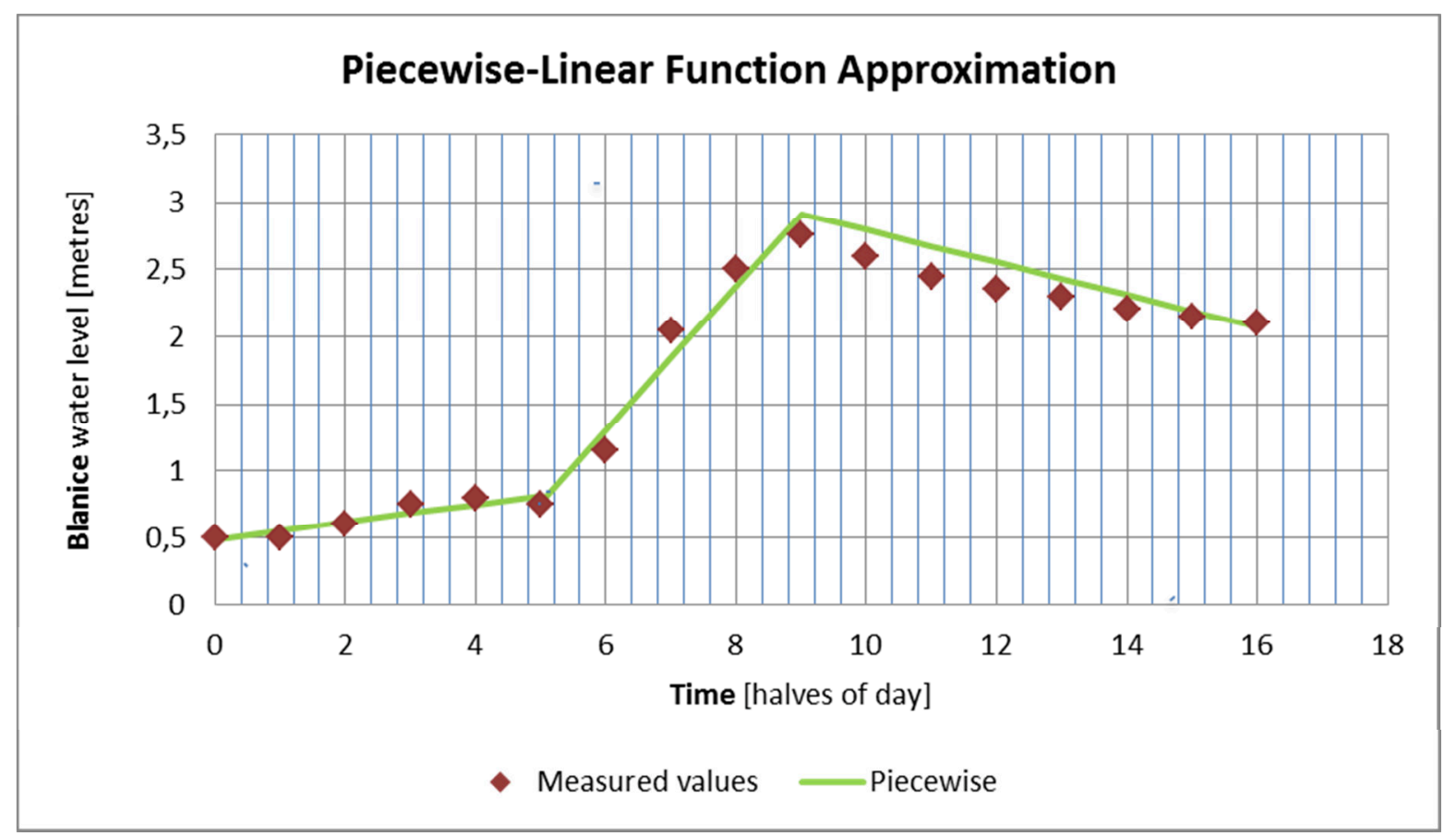

Source: own modelling

\section{Approximation by Other Seven Types of Functions}

The given data have been further approximated by the same seven types of functions as in case of the first case study using analogous procedure. Table 2 below contains formulas for the functions and standard errors of approximation by the least squares method using Maple 16 system.

Table 2 The Blanice River Water Level Data Approximation by Eight Types of Functions, Approximation Standard Errors and BIC

\begin{tabular}{|c|c|c|c|}
\hline $\begin{array}{l}\text { Approximation } \\
\text { function }\end{array}$ & $\begin{array}{l}\text { Rough formula of the approximation } \\
\text { function }\end{array}$ & $\begin{array}{l}\text { Stand.e } \\
\text { rror }\end{array}$ & BIC \\
\hline quadratic & $y=-0.01441 x^{2}+0.3693 x-0.009701$ & 1.473 & -26.501 \\
\hline cubic & $\begin{aligned} y=-0.002522 x^{3}+0.04612 x^{2} \\
+0.06495 x+0.4114\end{aligned}$ & 1.132 & 0.2794 \\
\hline linear-exponential & $y=0.3816+0.1776 x-0.000000152 \mathrm{e}^{\mathrm{x}}$ & 1.598 & -23.728 \\
\hline linear-logarithmic & $\begin{aligned} y=0.08008 & +0.04801 x \\
& +0.6151 \ln (x+1)\end{aligned}$ & 1.817 & -19.353 \\
\hline linear-irrational & $y=0.1094+0.03394 x+0.4953 \sqrt{x}$ & 1.853 & -18.701 \\
\hline
\end{tabular}


Table 2 (continued)

\begin{tabular}{|c|c|c|c|}
\hline $\begin{array}{l}\text { Approximation } \\
\text { function }\end{array}$ & $\begin{array}{l}\text { Rough formula of the approximation } \\
\text { function }\end{array}$ & $\begin{array}{l}\text { Stand.e } \\
\text { rror }\end{array}$ & $\overline{\text { BIC }}$ \\
\hline $\begin{array}{l}\text { linear- } \\
\text { goniometric }\end{array}$ & $\begin{aligned} y=0.5584+ & 0.1387 \\
& -0.01467 \cos x \\
& +0.08726 \sin x\end{aligned}$ & 1.928 & -14.215 \\
\hline broken rational & $\begin{aligned} y=2.9304- & 9.5033 /(x+1) \\
& +7.1608 /(x+1)^{2}\end{aligned}$ & 1.688 & -21.873 \\
\hline piecewise-linear & $\begin{array}{ll}y=0.0657 x+0.4857, & x \in\langle 0,5.09\rangle \\
y=0.535 x-1.905, & x \in\langle 5.09,8.63\rangle \\
y=-0.0905 x+3.4935, & x \in\langle 8.63,16\rangle\end{array}$ & 0.336 & -65.375 \\
\hline
\end{tabular}

Source: own calculation

The diagrams of all above-mentioned approximation functions are showed in Figure 9.

Figure 9: The Blanice River Water Level - Diagram of Data and Approximation Functions

\section{Blanice river}

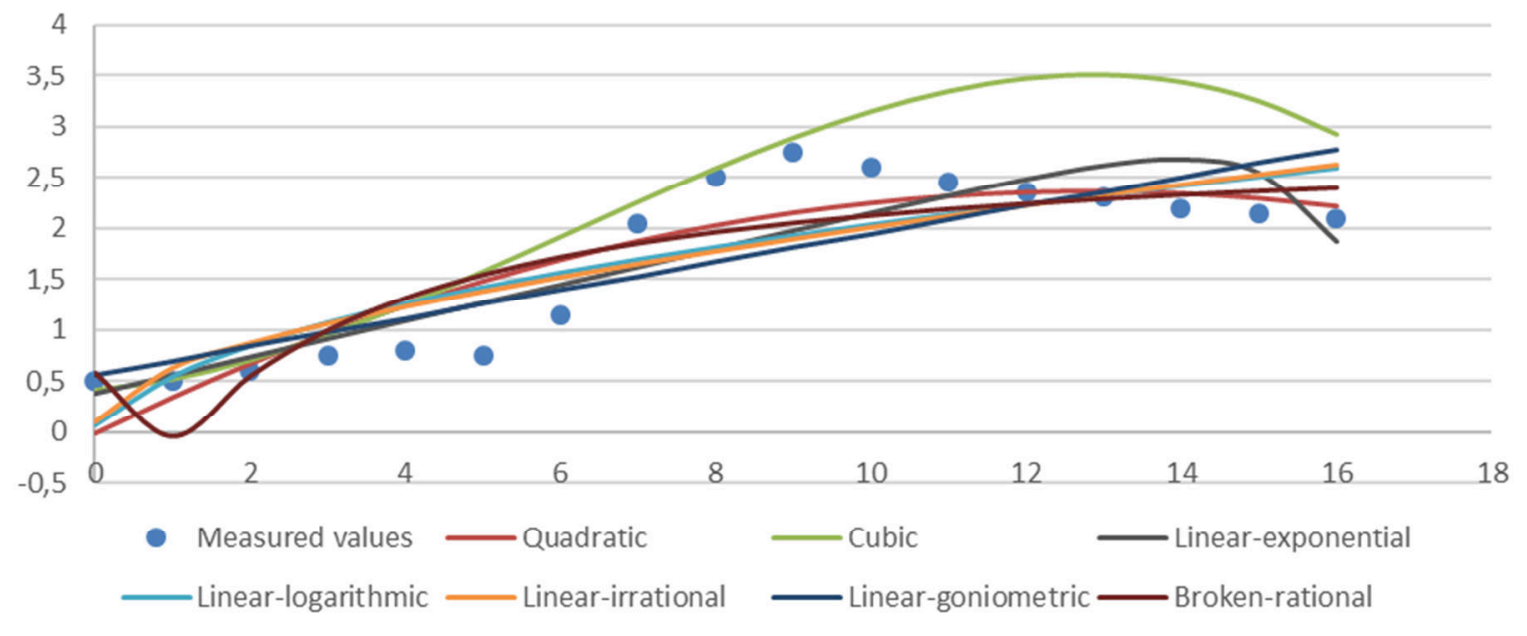

Source: own modelling

\section{DISCUSSION AND CONCLUSION}

Based on the comparison of approximation standard errors with the Bayesian information criterion and its outcomes shown in Tables 1 and 2 it may be stated that the piecewise-linear model of threat life cycle and risk dynamics presented at the beginning of the paper has been successfully verified on two sets of data as being the most suitable model out of all the considered approximations. The theoretical course (dynamics) of threat has been confirmed in individual phases of threat life cycle as indicated in Figure 2 "Threat life cycle dynamics" for a particular flood threat. The verification has been based on mathematical tools and tested data acquired during two floods (see Fig. 5 and Fig. 8). 
The primary lesson learned by crisis managers is that the proven threat dynamics development in each of its phases has a significant value that can consequently affect the whole process of dealing with the threat.

Mathematical and statistical verification based on available realistic data on the 2013 floods in the Czech Republic, confirmed a match between the theoretical assumption and the actual course - the threat life cycle dynamics. It has been proven that it is possible not only to model the progress value of risk in individual developmental stages of threat, but also, through collecting systemically the necessary data in the process of risk communication, to create a possible basis for predicting the threat life cycle in relation to the examined area, when exact statistical methods are applied. This approach would allow monitoring of the life history (life story) of a threat, which has been historically evolving in the given territory. Taking the above mentioned contexts into consideration could contribute to a better prediction of threats depending on the evolution of life of the society.

Ultimately, such awareness can contribute to the improvement not only in the crisis management process, but also in the allocation of necessary financial and material resources for the different developmental threat stages in the context of eliminating their negative impacts.

\section{Acknowledgement}

„The work was created in commission of the National University of Public Service under the priority project KÖFOP-2.1.2-VEKOP-15-2016-00001 titled „Public Service Development Establishing Good Governance" in (the) Ludovika Workshop/Ludovika Research Group/Győző Concha Doctoral Program/Miklós Zrínyi Habilitation Program/István Egyed Postdoctoral Program/Lajos Lőrincz Professor Program."

The second author has been supported within the project for "Development of Basic and Applied Research developed in the long term by the Departments of Theoretical and Applied Bases FMT (Project code: "VYZKUMFVT (DZRO K-217)") supported by the Ministry of Defence of the Czech Republic.

\section{REFERENCES}

Antušák, E., \& Kopecký, Z. (2003). Úvod do teorie krizového managementu I. Praha: Oeconomia. $21-27$.

Bumbová, A., Božek, F., \& Čáslavský, M. (2012). The Identifikation of Threats to the Source of Emergency Water Supply. PSAM \& ESREL 2012 Conference. Helsinky: PSAM \& ESREL. 1.

Erikson, E., (1980) Identity and the life cycle, W.W. Norton \& company,

Government of Czech Republic. (2003). Czech Security Strategy. Czech Security Strategy 2003. Prague, Czech Republic.

Hasilová, K. (2014). Iterative Method for Bandwidth Selection in Kernel Discriminant Analysis. In: 32nd International Conference Mathematical Methods in Economics MME2014. Olomouc: Palacký University, Olomouc, 2014, 263-268. 
Hendrickson, C., Horvath, A., Joshi, S., \& Lave, L. (1998), Economic Input-Output Models for Environmental Life-Cycle Assessment, POLICY ANALYSIS, April 1, 1998 / 32(7), 184 A-191 A

Jolliet, O., Margni, M., Charles, R., Humbert, S., Payet, J., Rebitzer, G., \& Rosenbaum, R. (2003). IMPACT 2002+: A new life cycle impact assessment methodology, The international journal of life cycle assessment, November 2003, 8(6), 324-330.

King, M. (2002) Security Lifecycle - Managing the Threat, GSEC Practical v1.3, January 14.

Katz, D., \& Kahn, R.L. (1978). The Social Psychology of Organizations. (Vol. 2). New York: Wiley. Retrieved from www. hrfolks. com

Levitt, T. (1965). Exploit the Product Life Cycle. Harvard Business Review, 43-81-96.

Písek Municipal Authority. (2013). Report About the Flood in Area of Písek Municipality in 2.6. - 12.6. 2013. Písek, Czech Republic.

Sedlačík, M., Odehnal, J., \& Foltin, P. (2015). Classification of Terrorism Risk by Multidimensional Statistical Methods. AIP Conference Proceedings. Melville: American Institute of Physics. 720011-1 - 720011-4.

Silva, M., \& Klutle, A. (2016). Reliability and Life Cycle Analysis of Deteriorating System, Springer: $\quad$ International Publishing Switzerland 2016, ISBN 978-3-319-20946-3.

Urban, R. (2014). Concept of Threat Life Cycle Dynamics in Theory of Crisis Management. March 2014, Brno, Czech Republic.

Urban, R. (2013). Risks and Risk Scenarios in Insurance Assessing Systems. In Urbánek, J. Crisis scenarios (Chapter 6). Brno: Monika Promotion.125 - 133.

Valis, D., Hasilova, K., \& Leuchter, J. (2016) Modelling of influence of various operational conditions on Li-ion battery capability, IEEE International Conference on Industrial Engineering and Engineering Management 2016-December, 7797933, pp. 536-540.

Votýpka, J. (2014). Výroční zpráva městského úr̆adu Písek za rok 2013. Retrieved March 2016, from Město písek: http://www.mestopisek.cz/VismoOnline_ActionScripts/File.ashx?id_org=12075\&id_do kumenty $=7655$ 